\title{
Endoscopic sphincterotomy - The basics
}

\author{
DS ZIMMON, MD
}

\begin{abstract}
Endoscopic sphincterotomy refers to the incision of the terminal portion of the biliary or pancreatic ducts by a variety of techniques, depending on anatomic circumstances, goals and risks. Alternative methods include percutaneous transhepatic or surgical techniques. The initial Erlangen method complete sphincterotomy - carried an unavoidable risk of perforation and hemorrhage. Fractional incision or 'endoscopic papillotomy' - incision of the inferior sphincter - carries no risk of hemorrhage or perforation, done properly. Techniques of papillotomy including 'pull,' 'precut,' stent placement, infundibulotomy, percutaneous cholangiography, and internal spring wire are described, and general electrosurgical principles discussed. Can J Gastroenterol $1990 ; 4(9): 559-563$
\end{abstract}

Key Words: Endoscopy sphincterotomy, ERCP, Risks, Technique

\section{La spinctérotomie endoscopique - Principes fondamentaux}

RESUME: La sphinctérotomie endoscopique est un terme général décrivant l'incision du segment terminal des canaux biliaires ou pancréatiques, selon diverses techniques adaptées aux circonstances anatomiques, aux buts visés et aux risques encourus. Les techniques transhépatiques percutanées ou chirurgicales constituent d'autres méthodes possibles. A l'origine, la méthode d'Erlangen (ou sphinctérotomie complète) comportait un risque inévitable de perforation et d'hémorragie, qu'exclut l'incision fractionnaire ou papillotomie endoscopique correctement exécutée. L'auteur décrit les techniques de la papillotomie "traction", "pré-coupe", mise en place de l'écarteur, infundibulotomie, cholangiographie percutanée et tige métallique à ressort, et il examine les principes électrochirurgicaux d'ordre général.

New York University School of Medicine, New York, New York, USA

Correspondence and reprints: Dr DS Zimmon, 36-7th Avenue, Suite 516, New York, NY 11050, USA
E NDOSCOPICSPHINCTEROTOMY IS A general term applied to a variety of techniques used to incise the terminal portion of the biliary or pancreatic ducts. Vast developments of technique, indications and goals have been achieved by endoscopic sphincterotomy since its origination by Erlangen in $1974(1,2)$. The specific methods and devices required vary considerably according to the anatomic circumstances, goals and risks in comparison to alternative methods such as percutaneous transhepatic or traditional surgical techniques. The initial Erlangen method for endoscopic sphincterotomy required deep insertion of a long wire sphincterotome into the bile duct. The sphincterotome was then bowed taut and with a single rapid cut the entire sphincter was incised. This complete 'endoscopic sphincterotomy' used fluoroscopic control and carried an unavoidable risk of duodenal perforation and hemorrhage due to incision of the retroduodenal artery.

In the more hostile environment of the United States, the author developed a short lax wire technique to 


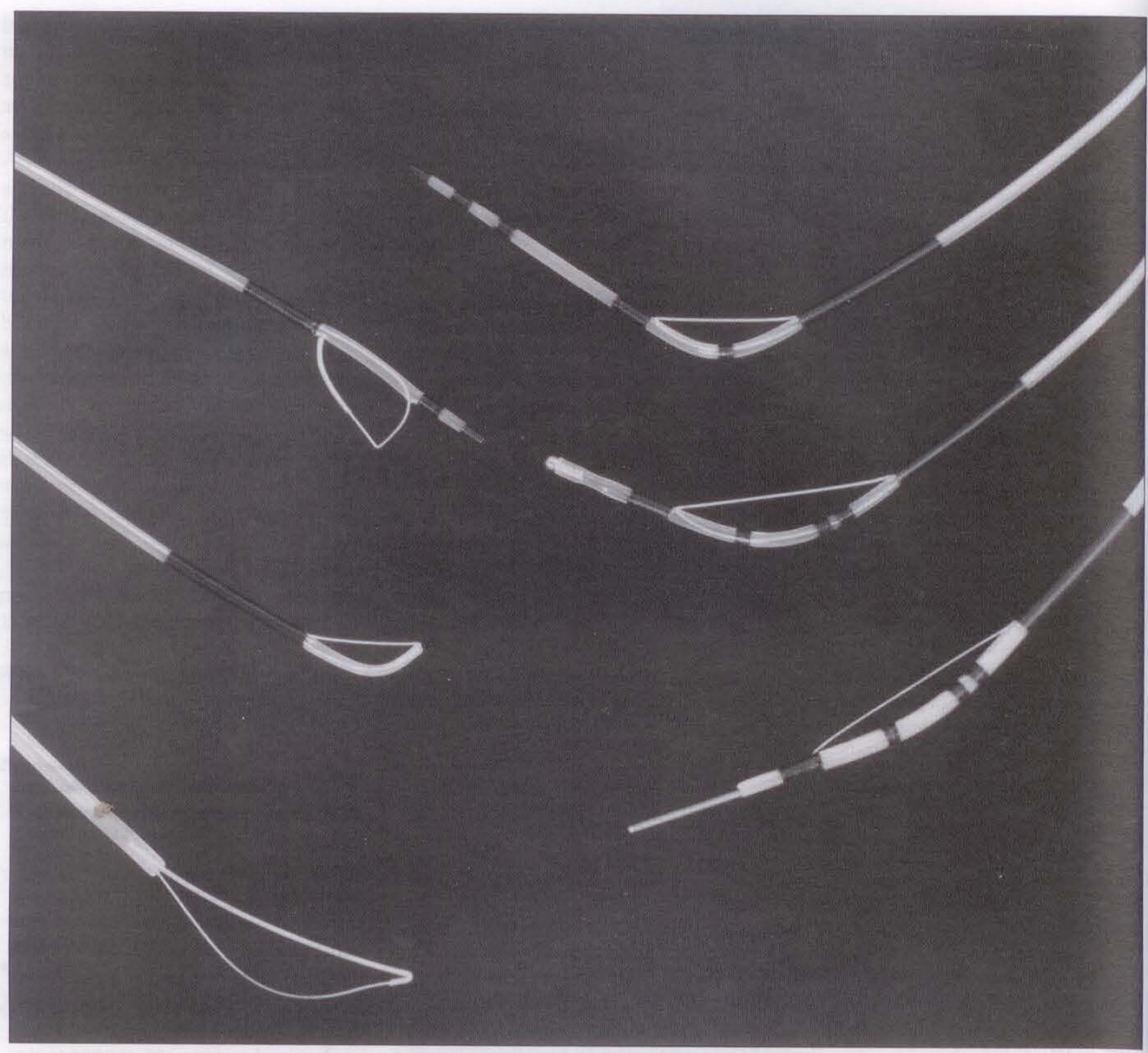

Figure 1) A variety of specialized papillotomes Clockwise from top: Elongated taper tip $20 \mathrm{~mm}$ cutting wire; Metal ball tip $30 \mathrm{~mm}$ cutting wire; Wireguided (wire in place) papillotome $7 F$ with $30 \mathrm{~mm}$ cutting wire; Papillotome for Billroth II gastrectomy (Sohendra type) with $7 F$ guide tube; Precut papillotome $20 \mathrm{~mm}$ with cutting wire at catheter tip; Shark fin papillotome

be used for fractional incision of the inferior and submucosal sphincters, unless deeper more dangerous incision of the proximal sphincter was specifically required. In an attempt to differentiate the two techniques, the smaller incision was called 'endoscopic papillotomy' (3). These terms are often interchanged although the incision lengths and risks are quite different. Presumably, the initial Erlangen technique is no longer in use, and both terms now refer to the fractional method. This technical bias is not supported by any objective study (4).
The vast difference in technique between sphincterotomy and papillotomy is reflected in the different devices used (Figure 1). Sphincterotomy used a single strand 30 or $40 \mathrm{~mm}$ wire pulled into a taut bow after deep insertion in the bile duct. The rate of incision was difficult to control. High power was required because of the long wire in contact with tissue. Hemorrhage and clinically significant perforation were acknowledged risks even though mortality was substantially less than that for traditional abdominal surgery. By con- trast, endoscopic papillotomy uses a lax braided wire $20 \mathrm{~mm}$ in length with an insertion depth of 5 to $10 \mathrm{~mm}$. The depth of insertion is controlled by visible marks on the sphincterotomy catheter.

The initial incision is made with 5 $\mathrm{mm}$ of wire in contact and therefore requires less current. For removal of a small stone, incision of a distal stenosis, separation of the biliary and pancreatic ducts to prevent recurrent gallstone pancreatitis or facilitation of stent placement, only the inferior sphincter 
is incised. If the sphincterotome is properly placed in the bile duct, the risk of hemorrhage or perforations is nil. The major hazard is pancreatitis, probably due to inaccurate insertion of the device into the pancreatic duct, excess current flow to the pancreas or trauma to a minute adjacent pancreatic duct. Current flow is limited by the small amount of wire in contact and the brief duration of incision. Since no large blood vessels are near a 'cut' with minimal tissue damage, injury is limited to the nearby pancreatic duct.

The recent development of lithotripsy techniques for the management of large stones makes full sphincterotomy infrequently necessary. Usually, incision of the inferior sphincter - and a small portion of the superior sphincter - when required allows lithotripsy and extraction of smaller stone fragments (Table 1).

\section{TECHNIQUES AND DEVICES}

The advantage of the pull type of sphincterotome is accurate incision from inside the duct system with visual control. This device may be modified in a number of ways. The cannulating tip may be tapered or elongated to facilitate selective bile duct cannulation. A 2.5 to $3.5 \mathrm{~cm}$ length of lead reduces stiffness created by the sphincterotomy wire even when soft braided wire is used to facilitate selective bile duct cannulation. Cannulation with the standard device can sometimes be aided by bowing of the wire. The long lead limits bow formation during papillotomy. If the lumen is narrow, this is no disability. As the lumen widens, lack of bow formation makes it difficult to incise the roof of the papilla. Additionally, lack of bow formation makes orientation within the duodenum and bile duct more difficult. A long lead also necessitates deep bile duct cannulation to permit cutting wire contact, and therefore cannot be used when impacted stones or neoplastic disease prevent deep cannulation.

When selective bile duct cannulation cannot be achieved, the 'precut' papillotomy device may be used. For a precut, the cutting wire originates at the tip of the cannulating catheter.
This device is more difficult to orient and increases the risk of extending the incision in the wrong direction unless the specific appropriate anatomic circumstance is present. A precut is useful when the papilla is displaced medially in the duodenum. Usually because the papilla is low in the duodenum or a pancreatic mass superiorly angulates the bile duct, deep cannulation is prevented. The precut incises a short distal segment, straightening the angle. It is wise to identify the appropriate anatomy by prior cholangiopancreatography to avoid unintentional incision of the pancreatic duct.

An important alternative, particularly in the difficult bile duct cannulation associated with neoplastic disease, is the placement of a biliary stent. After duct opacification (or sometimes without) a $35 \mathrm{~K}$ guidewire with a soft tip is advanced into the duct system. A biliary stenosis can be dilated and contrast media injected or a stent placed. After the stent is in place, papillotomy is performed using the end cutting sphincterotome. This device has the wire exiting the tip to allow precise knife-like incision along the 11 o'clock border of the stent. After incision of the inferior sphincter, the stent may be removed and the incision extended or a larger stent placed as necessary.

The end cutting device is also useful for the performance of the "infundibulotomy.' The bile duct infundibulum is the portion above the sphincter within the intraduodenal bile duct. This is easily identified in patients with terminal bile duct obstruction due to stones or neoplasia because it is dilated and soft. This segment is emphasized when there is a long intraduodenal bile duct. Conversely, in patients with a short intraduodenal bile duct the infundibulum may be absent or difficult to identify and immediately adjacent to the pancreatic duct. It is therefore useful to opacify this segment before puncturing it. Puncture is performed under both visual and fluoroscopic control. After puncture, bile flows into the duodenum. With light pressure, the specially designed infundibulotomy device enters the infundibulum and passes directly into the bile duct. The
TABLE 1

Use of endoscopic sphincterotomy

Facilitates repeated access to biliary tree at low risk

Aids identification and cannulation of pancreatic duct

Facilitates spontaneous passage of stones

Defunctionalizes gallbladder by reducing biliary to duodenal pressure gradient

Prevents recurrence of gallstone pancreatitis by separating biliary and pancreatic ducts

Allows biopsy of distal biliary mucosa and submucosal tissue

electrode is then removed from the catheter and a stenting wire may be passed before or after injection of contrast. The catheter may be removed, leaving the $35 \mathrm{~K}$ wire in place, and an appropriate stent placed through the infundibulotomy into the bile duct. The incision may be extended as required either proximally or distally. Alternatively, a sphincterotome may be placed through the infundibulotomy orifice and the incision extended in the usual fractional fashion. In patients with a small terminal bile duct neoplasm who are candidates for surgical resection, this is an ideal and safe method for achieving complete biliary decompression with resolution of jaundice prior to surgery, as it avoids the risk of bleeding due to incision of the tumour. A similar procedure may be used for performing endoscopic sphincterotomy in patients with Billroth II gastrectomies. After cholangiography, a biliary stent may be placed and infundibulotomy performed. Alternatively, an easily identified infundibulum may be punctured for both opacification and sphincterotomy. In the patient with a Billroth II gastrectomy, a standard sphincterotome is easily passed prograde from the infundibulotomy through the sphincter. This allows the sphincterotomy to be performed 'proximal to distal' under anatomic control in these sometimes difficult problems. An alternative of stent placement followed by fractional sphincterotomy using the infundibulotomy device can also be used.

When bile duct cannulation fails, a 
choice between alternate methods of percutaneous cholangiography with stent placement or precut incision of the sphincter is required. Careful incision of the distal mucosa with an $18 \mathrm{~K}$ end cutting sphincterotomy device allows identification of the terminal bile duct and may facilitate cannulation. This technique often requires a second or even third procedure to enter the ducts. In the absence of considerable experience, the alternative of percutaneous cholangiography with stent placement allows identification of distal pathology and makes it possible to differentiate a disease state from simple technical failure of cannulation. As previously noted, precut sphincterotomy, particularly in the absence of anatomic definition, carries a greater hazard than alternative procedures.

A variety of highly specialized sphincterotomy devices have been developed for use in the Billroth II gastrectomy or other special circumstances. These include the Sohendra reverse curve, the Cremer sigmoid sphincterotome or the shark fin papillotome.

Additional modification of the sphincterotomy devices includes an internal spring wire. This allows precise feedback control of bow tension during sphincterotomy. Initial cannulation is usually not performed with this device because of its stiffness. After initial papillotomy, the spring-loaded device is introduced to perform a carefully directed and more dangerous incision of the proximal sphincter under maximal visual and mechanical control. In contrast to the initial incision usually made with only 5 to $10 \mathrm{~mm}$ of wire within the sphincter and a small $(20 \mathrm{~mm})$ bow, the spring-loaded $30 \mathrm{~mm}$ sphincterotome permits careful incision of a gaping orifice. Caution not to breach the duodenal wall must be exercised if perforation and hemorrhage are to be avoided - here lithotripsy techniques should be used. Nevertheless, a large sphincterotomy is useful for removing fragments that remain after lithotripsy.

The 5 and 7 French wireguided sphincterotomes solve the problem of re-entering the bile duct after a difficult cannulation. A soft tip wire guide (420 $\mathrm{cm}$ ) identical to that for stents is passed through the standard cannulating catheter into the proximal duct system after bile duct cannulation, or even when contrast cannot be injected. If a tapered tip cannula is used, an $18 \mathrm{~K}$ wire-guide is required. Rather than placing a stent or drain, or dilating with a balloon or wireguided dilator, the papillotome is passed over the guide to both dilate and position the cutting wire. The 7 French double channel device electrically separates the wire guide from the sphincterotome. This permits completion of the sphincterotomy without removal of the wire guide. By leaving the wire in place, one may move the sphincterotome out of the duct to determine lumen size without risk of displacement. Furthermore, after completion of the incision, this sphincterotome may be removed with. out removal of the wire guide and extraction balloons or stents introduced over the wire guide. A complete procedure may be performed with a $35 \mathrm{~K}$ wire guide in place following single bile duct cannulation. Maintaining the wire guide in position requires a team practised with catheter changes and careful maintenance of endoscopic position. This is a valuable technique for stent placement in neoplasia or when the papilla of Vater is within a diverticulum.

The 5 French wireguided sphincterotome has similar advantages. However, the sphincterotomy wire and the wire guide are not electrically isolated, and it is wise to remove the wire guide before performing sphincterotomy.

\section{GENERAL ELECTROSURGICAL PRINCIPLES}

Endoscopic sphincterotomy uses 80 to $100 \mathrm{~W}$ of electrosurgical power. In contrast, polypectomy uses uses 15 to 25 $\mathrm{W}$ in a field that is dry with control of polypectomy loop size. In polypectomy the initial current application dries the field and allows for controlled coagulation and incision. The field is always wet in endoscopic biliary and pancreatic electrosurgery. It is, therefore, important to control the length of cutting wire in contact with tissue and its pressure against the tissue. Excessive pressure produces a rapid and uncontrolled cut. If an excessive length of wire is in contact with tissue, high power preceded by tissue drying is required to initiate the cut. Again, the length and speed of the incision is difficult to control under these circumstances. Excessive current flow may be a factor producing pancreatitis, since pancreatic tissue surrounds the terminal bile duct. With 5 to $10 \mathrm{~mm}$ of wire in contact, a series of rapid fractional incisions can be made with low current flow and visual control. Sparking, burning or fragmentation of wire occurs if too much power is applied. A minimum $5 \mathrm{~mm}$ of wire in contact prevents sparking. It is difficult to use the longer 30 to $40 \mathrm{~mm}$ devices because they tend to contact the endoscope, causing a short circuit which burns and fragments the wire. The mechanical and electrosurgical characteristics of a sphincterotome are changed after use by heating of the wire and the catheter. Charring of the wire surface also changes the characteristics of the cut. Reliable reproducible results can only be achieved with a bright wire on first use. If a technical error deforms the device, it should be replaced before attempting to complete the procedure.

If it is necessary to incise the more proximal portion of the sphincter, a spring-loaded sphincterotome at the incisional apex provides the best mechanical and electrical control. A slow incision with pressure to coapt the larger vessels limits the risk of perforation and hemorrhage. Careful fluoroscopic control should be exercised to ensure that retroperitoneal air is immediately recognized. A small air leak seals in 24 to $48 \mathrm{~h}$ with little consequence. If the initial perforation is not recognized and the incision extended, duodenal perforation with all of its complications will occur $(5,6)$.

\section{CONCLUSION}

There is now a vast array of techniques and devices for the safe and successful performance of endoscopic sphincterotomy and its associated therapeutic techniques of stent placement, lithotripsy and intraluminal radi- 
ation. Careful analysis of the endoscopic and radiologic anatomy of the duodenum, biliary and pancreatic ducts is required for safe and successful application of these methods. Alternative procedures such as percutaneous cholangiography and surgery must be considered. This field continues to evolve rapidly. As clinical and technical skills develop, a successful solution to the clinical problem will be reached more quickly and safely than ever before.

\section{REFERENCES}

1. Classen M, Demling L. Endoskopische Sphinkterotomie der Papilla Vateri und Steinextraktion aus dem Ductus choledochus. Dtsch Med Wochenschr 1974;99:496-7.

2. Kawai K, Akasaka Y, Murakami K, et al. Endoscopic sphincterotomy of the ampulla of Vater. Gastrointest Endosc 1974;20:148-51.

3. Zimmon DS, Falkenstein D, Kessler RE. Endoscopic papillotomy for choledocholithiasis. N Engl J Med 1975;293:1181-2

4. Zimmon DS. Endoscopic management of biliary calculi. Hosp Pract 1978; 13:103-14

5. Reiter JJ, Bayer HB, Mennicken C, et al. Results of endoscopic papillotomy: A collective experience from 9 endoscopic centers in West Germany. World J Surg 1978;2:505-7.

6. Neoptolemos JP, Carr-Locke DL, London NJ, et al. Controlled trial of urgent endoscopic retrograde cholangiopancreatography and endoscopic sphincterotomy versus conservative treatment for acute pancreatitis due to gallstones. Lancet 1988;ii:979-83. 


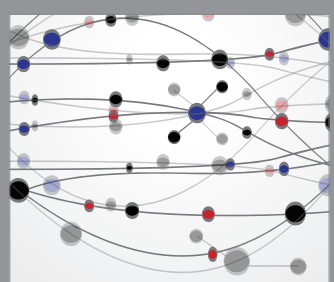

The Scientific World Journal
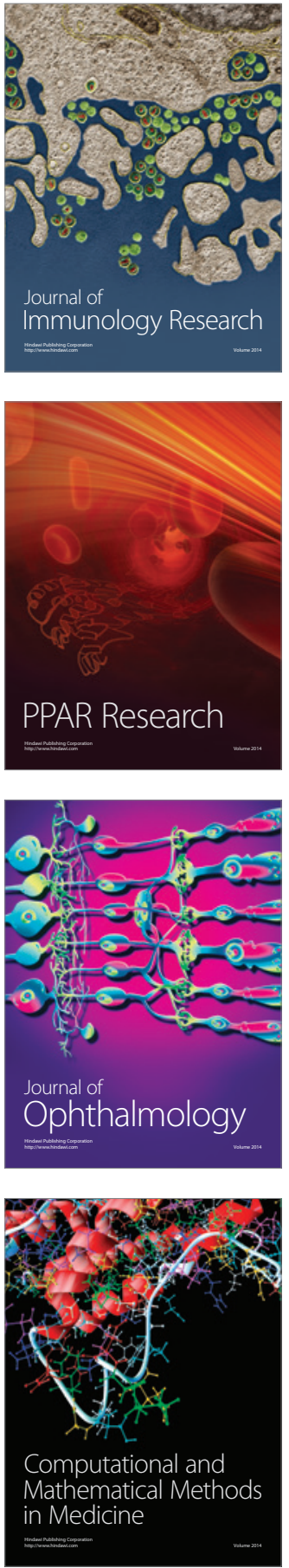

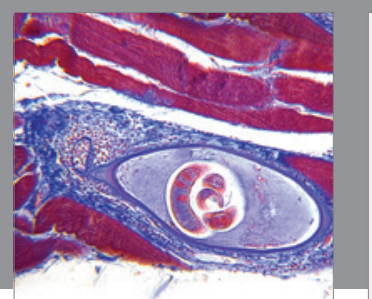

Gastroenterology Research and Practice

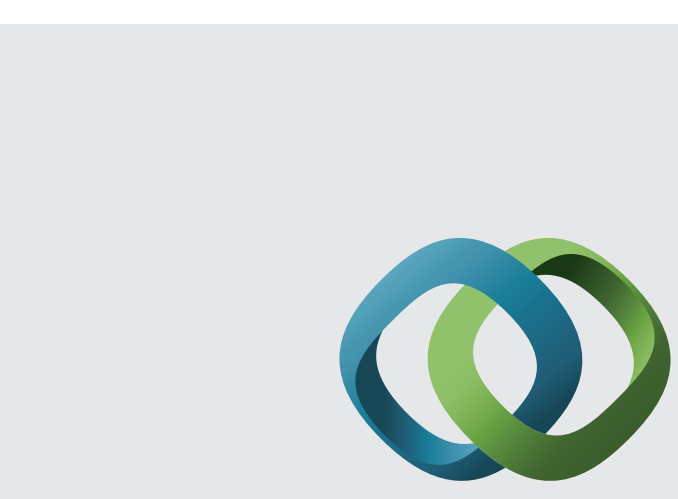

\section{Hindawi}

Submit your manuscripts at

http://www.hindawi.com
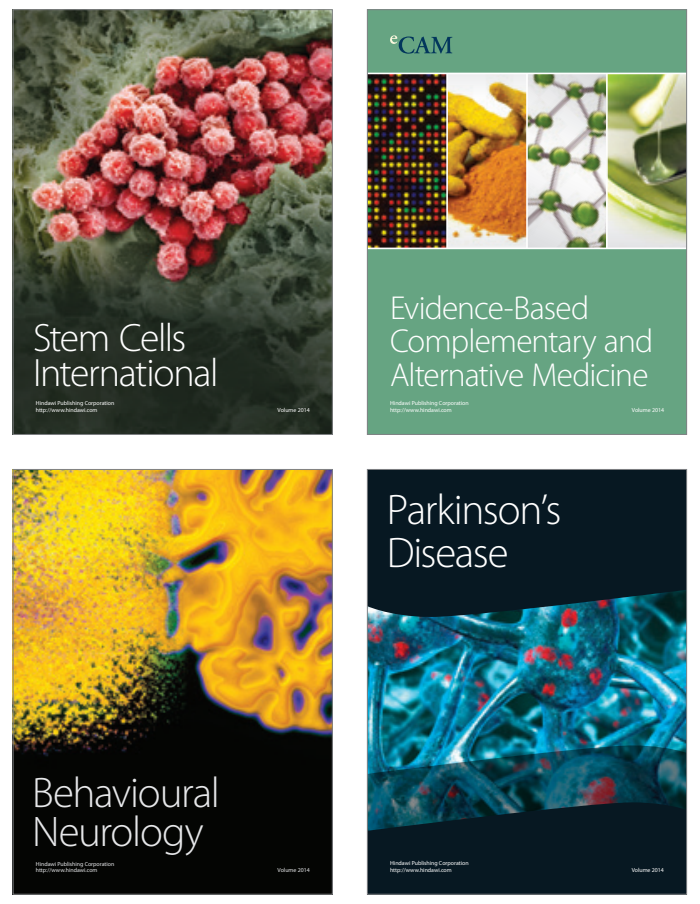
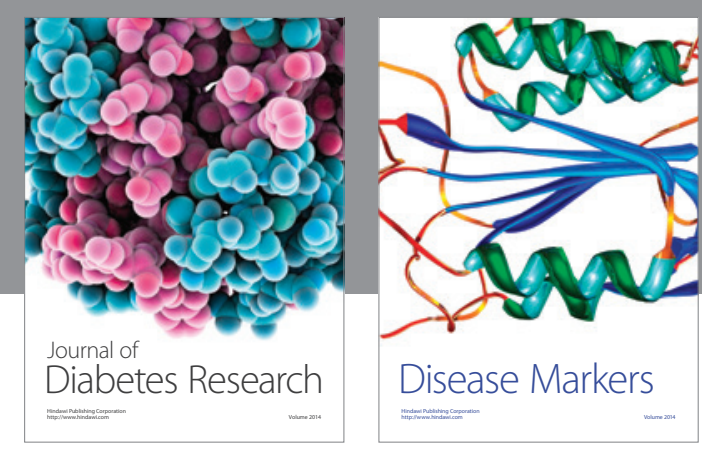

Disease Markers
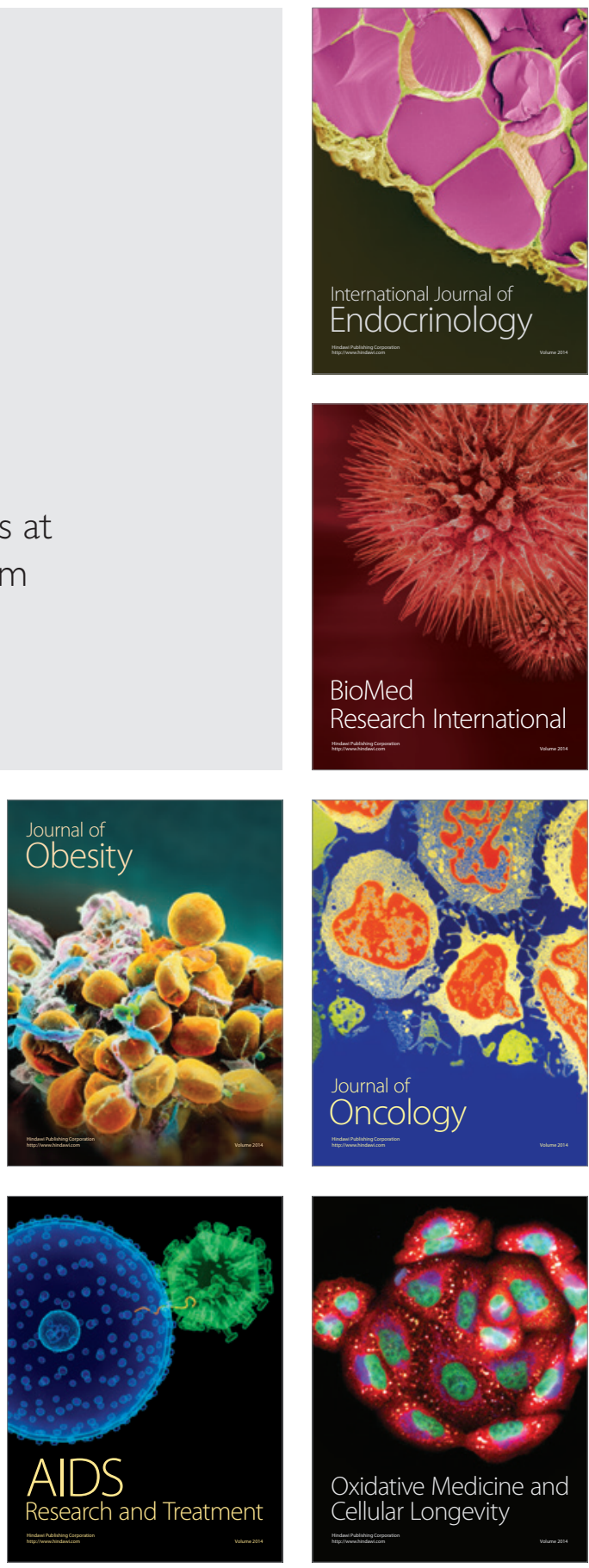